\title{
Impacts on Head Start Dual Language Learning Children's Early Science Outcomes
}

\author{
Brooke Rumper ${ }^{1, *(D)}$, Elizabeth Frechette ${ }^{2}$, Daryl B. Greenfield ${ }^{3}$ and Kathy Hirsh-Pasek ${ }^{1,4}$ (D) \\ 1 Department of Psychology, Temple University, Ambler, PA 19002, USA; khirshpa@temple.edu \\ 2 Early Childhood Education Institute, University of Oklahoma-Tulsa, Tulsa, OK 74135, USA; \\ e.frechette@ou.edu \\ 3 Department of Psychology, University of Miami, Coral Gables, FL 33146, USA; dgreenfield@miami.edu \\ 4 The Brookings Institution, Washington, DC 20036, USA \\ * Correspondence: brooke.rumper@temple.edu
}

Citation: Rumper, B.; Frechette, E.; Greenfield, D.B.; Hirsh-Pasek, K. Impacts on Head Start Dual

Language Learning Children's Early Science Outcomes. Educ. Sci. 2021, 11, 283. https://doi.org/10.3390/ educsci11060283

Academic Editor:

Konstantinos Ravanis

Received: 18 May 2021

Accepted: 30 May 2021

Published: 7 June 2021

Publisher's Note: MDPI stays neutral with regard to jurisdictional claims in published maps and institutional affiliations.

Copyright: (c) 2021 by the authors. Licensee MDPI, Basel, Switzerland. This article is an open access article distributed under the terms and conditions of the Creative Commons Attribution (CC BY) license (https:/ / creativecommons.org/licenses/by/ $4.0 /)$.

\begin{abstract}
The present study examined the roles that language of assessment, language dominance, and teacher language use during instruction play in Dual Language Learner (DLL) science scores. A total of 255 Head Start DLL children were assessed on equated science assessments in English and Spanish. First overall differences between the two languages were examined, then associations between performance on science assessments were compared and related to children's language dominance, teacher quantity of English and Spanish, and teachers' academic science language. When examined as a homogeneous group, DLLs did not perform differently on English or Spanish science assessments. However, when examined heterogeneously, Spanish-dominant DLLs performed better on Spanish science assessments. The percentage of English and Spanish used by teachers did not affect children's science scores. Teachers' use of Spanish academic science language impacted children's performance on science assessments, but English did not. The results have implications for the assessment of DLLs and teacher language use during instruction.
\end{abstract}

Keywords: early science education; dual language learners; low-income; teacher language use; preschool

\section{Introduction}

Throughout the United States, the number of jobs in Science, Technology, Engineering, and Math (STEM) is on the rise [1,2]. However, Hispanic people are disproportionately underrepresented in STEM careers [3]. While they make up 18\% of the population in the US [4], they hold only $7 \%$ of STEM jobs [2,3]. Thus, there is a need to ensure that early educational experiences are providing opportunities for young Hispanic children to build foundational knowledge in the STEM domains [5]. The current study aims to investigate the assessment methodology used to measure early science learning for young Hispanic Spanish-English Dual Language Learning (DLL) children. Previous studies that include DLL children typically determine language of assessment through a single method (e.g., teacher or parent report) [6]. However, many factors (e.g., teacher language use) influence DLL children's development and could play a role in determining which language(s) are appropriate for assessing them. Furthermore, decisions about language of assessment could potentially impact inferences made about DLL children's development. Thus, the present study examines how the language of assessment, dominant language, and teacher language use impact Hispanic Spanish-English speaking children's performance on a measure of early science learning.

The current study aims to shed light on the early science experiences of Hispanic Spanish-English DLL children. DLLs are defined as children, typically under the age of eight, who are learning two languages $[7,8]$. DLL children's languages can be learned simultaneously (i.e., began learning both before age three) or sequentially (i.e., began learning one before age three and one after age three) [9]. While not all Hispanic children 
learn Spanish, the present study focuses on the subset of preschool children who are learning English and Spanish, as they are disproportionally more likely to live in underresourced homes [10-12]. This puts them at greater risk for an early achievement gap across learning domains such as language, math, and science that persists and widens over time [13-15].

Despite these trends, it is important to note that learning two languages in and of itself is not a liability for academic achievement. There are a great many strengths associated with bilingualism [16-18]. However, the strengths that young Spanish-English DLL children bring into their classrooms are often overlooked in assessment practices. Typically, research surrounding achievement gaps is based on assessments of children in English. This narrow view of achievement may disproportionally misrepresent the performance of SpanishEnglish DLL children. There may be a need for researchers and practitioners to take a strengths-based approach in assessing their knowledge. More specifically, children are often assessed in one language (as opposed to English and Spanish), while their dominant language and language use during instruction are frequently disregarded entirely. Assessment practices around DLL children have been examined in the context of language skills (e.g., vocabulary, syntax) $[19,20]$; however, nothing is known about how these factors might impact early science performance. Given the dynamic nature of learning two languages and the need for early support in science, it is critical to examine best assessment practices in science for young Spanish-English DLL children from under-resourced homes.

\subsection{Theoretical Framework}

The bioecological model [21] states that children are nested within a particular environment. Multiple factors in the environment interact with one another and play a role in children's development. Children are nested within communities, classrooms, and households, all of which impact a DLL's language use and development. In turn, DLL children interact with others in these contexts, in that way contributing to shaping their environment. For example, bilingual teachers could choose to use more Spanish, to better support children's learning in classrooms where the majority of their students are Spanish speaking. Likewise, given this theory [21], if a DLL child grows up in a community where their home language is not used frequently, over time, they may shift toward using their other language more. Conversely, in communities such as Miami-Dade County where this study was conducted, and where Spanish is widely spoken in the community (i.e., by $66 \%$ of the population), such a shift may be less likely [22].

In the context of assessment, the bioecological model [21] points to multiple factors that could affect DLL children's performance. At a higher level, decisions about the language of assessment can influence children's scores. For example, researchers and practitioners who only have monolingual English-speaking staff can only assess DLL children in English. Additionally, assessments may only be available in one language. Such factors, in turn, interact with DLLs on an individual level. Some DLL children could be English dominant and perform well on English assessments, while others may be stronger in Spanish. In such circumstances, the language of assessment could potentially obfuscate children's actual knowledge. Furthermore, contextual factors such as teachers' language use could impact children's ability to understand content-specific vocabulary and concepts. For example, if a DLL child who is stronger in Spanish enters a predominantly Spanishspeaking classroom, they may better grasp the content that is taught than if they had entered a mainly English-speaking classroom.

The bioecological model [21] also applies to early science environments. External factors in the community and at home interact with a child's natural curiosity. If this curiosity is fostered over time, children may maintain a spirit of inquiry. Similarly, if scientific inquiry is supported more in one language (e.g., Spanish) than another (e.g., English), DLL children may perform better when assessed in Spanish than they would in English. The current study aims to understand what factors might influence SpanishEnglish DLL children's science outcomes. 


\subsection{Methodology of DLL Assessment as a Factor in Performance}

As the bioecological model [21] suggests, there are many factors for researchers and practitioners to consider when developing strategies to assess DLLs $[6,20,23]$. The current paper examines several of the strategies typically used in DLL assessment. The first is to assess DLL children in both of their languages (e.g., [24]). However, there is often a lack of resources (e.g., time, appropriately validated measures, or personnel to administer assessments in both languages) to do so. Another strategy is to assess DLL children in their most proficient, or dominant language. A third approach is to assess DLLs in the language of instruction. This final method is often used in the K-12 education system. Considering all of these strategies is important as the decision often impacts how DLL children are evaluated in their early educational settings. However, given the increased number of DLLs and the growing focus on science in preschool, this study aims to examine how assessment strategy impacts DLL children's performance on a measure of science learning.

\subsection{Early Science Education for DLL Children}

While few studies in the US have examined preschool DLL children's early science learning experiences [5], research has demonstrated that science is an ideal domain for several key reasons $[25,26]$. First, science instruction offers DLL children opportunities for hands-on learning, which decreases the cognitive load allocated to language $[25,27]$. Essentially, having materials physically present for DLL children to manipulate and engage with (e.g., magnifying glasses, blocks, and ramps) aids in learning overall and in learning new words across languages. Teachers can use language to label, describe, and help children to use materials in context, grounding and strengthening DLL children's understanding of science and language. Second, scientific inquiry is collaborative. Finding answers to scientific questions often involves the help of others. Children can be given opportunities to work together and to communicate with peers or teachers while solving problems (e.g., how to make a marble turn a corner in a block and ramp structure). Third, scientific inquiry can be documented and communicated in various ways and does not solely depend on expressive language. Science inquiry or understanding can be exhibited through children's drawings, graphs, and actions. Finally, DLL children bring their cultural understandings and family funds of knowledge into early scientific inquiry $[28,29]$. Children's questions about the world are sparked by their own experiences (e.g., "Why are there so many iguanas on the road?"). Through science, educators can incorporate children's questions and experiences into learning activities (e.g., "Why do you have to take a plane to visit Colombia?"). Given the promise around science as a learning domain for DLL children, the current study sought to understand factors that might contribute to best practices for assessment in early science. Specifically, this study investigated the impacts of the language of assessment, language dominance, and teachers' use of language (i.e., English and Spanish as well as academic science language) on science outcomes.

\subsection{The Roles of Language of Assessment and Dominant Language in DLLs' Performance}

Language of assessment and dominant language are important factors to account for in measuring DLL children's outcomes $[6,20,23]$. Although Spanish-English DLL children are all learning the same two languages, they are a very diverse group with respect to their individual language learning patterns and proficiency $[9,30]$. Differences in initial language acquisition and levels of exposure place DLL children at varying proficiencies in their two languages. Depending upon language dominance, children score differently on versions of assessments [24,31,32]. For example, one study [32] found that Spanish-dominant DLLs scored better at preschool entry on measures of Spanish vocabulary than English vocabulary [32]. Similarly, English-dominant DLLs scored better at preschool entry and exit on measures of English vocabulary than Spanish vocabulary. However, depending on exposure to English and/or Spanish during preschool, differences between children's language abilities can narrow [32,33]. Studies have found that Spanish-dominant preschoolers make gains in their English language skills in preschool classrooms, narrowing the gap between 
their languages [32-34]. A shift in dominance, however, is generally not detectable until children have been exposed to several years of English [35]. This indicates that language dominance and language of assessment could both impact children's performance on science assessments in preschool.

Though research has been conducted examining DLL children's differential performance on measures of English and Spanish language [32,33], to the authors' knowledge, there are no studies examining differences in science performance. Notably, while some aspects of science assessment rely on language, some components go above and beyond language. For example, while a child may not know the name of a magnifying glass, they may understand how to use it. This knowledge that occurs over and above vocabulary and language skills [25] speaks to the depth of understanding a child has about the content, thus making it important to understand the impacts that dominant language and language of assessment could have on DLL children's science performance. The current study aims to address this gap in the literature by investigating factors such as the language of assessment and language dominance, which may impact DLL children's scores on English and Spanish science assessments.

\subsection{Use of Spanish in Preschool Classrooms}

In addition to DLL children's own language abilities and language of assessment, other early environmental factors may play a role in early science performance. In particular, classroom language use has been found to impact DLL children's outcomes [34,36-38]. While little is known about the impacts of the language of instruction on DLLs during science lessons, prior studies have examined the effects of overall English and Spanish use within preschool classrooms. The use of home language (i.e., Spanish) along with English in the classroom has been associated with better outcomes for DLL children [34,36-38]. Supporting DLL children's English and Spanish helps to promote bilingualism, thus supporting their cognitive development $[17,39]$. Moreover, past research has demonstrated that when more Spanish is used in the classroom, DLL children have better social-emotional [36,40], reading, math [34], and language skills [37,38] compared to their counterparts whose teachers used less or no Spanish. In the preschool years, early education programs (e.g., Head Start performance standards) highlight a need to provide support to DLL children in Spanish and English [41]. This policy reflects findings in DLL research that fostering a strong home language helps children to develop strong English skills [31,42-44]. However, the use of Spanish in classrooms may vary widely, and to date, no studies have examined how Spanish use during science instruction might impact children's science outcomes.

Prior studies, not specific to science education, report little to no Spanish occurring on average in classrooms containing DLL children [34,36,37,45,46]. Many of these studies fully occurred in or involved Head Start funded programs [34,36,37,45,46]. Thus, due to Head Start performance standards, there should be some evidence of support of English and children's home language [41]. However, many studies have reported a large number of classrooms containing DLL children where teachers do not use Spanish at all $[34,36,37,45,46]$. For example, one study [36] found that DLL children in $23 \%$ of classrooms were exposed to no Spanish, and $18 \%$ heard very little Spanish (i.e., $<5 \%$ of the time). Similarly, another study [37] found even less Spanish being used in classrooms and that it was mainly used to give behavioral feedback or directions to children [37]. Additionally, children who maintained high levels of Spanish across the school year received instructions in Spanish, on average, 32\% of the time [34]. However, about a third of teaching teams used no Spanish during instruction. Together, these studies indicate that despite evidence that using Spanish is important for children's outcomes, it is generally used infrequently in preschool classrooms comprising Spanish-English DLL children. Given the dearth of literature around preschool teachers' Spanish and English use during science instruction specifically, the current study aims to examine how these factors might impact children's science outcomes. 


\subsection{Importance of Academic Language}

In addition to the sheer quantity of English and Spanish used during science lessons, research in other learning domains suggests that the quality of language is an important factor in children's outcomes [14]. That is to say that the quality of the science-specific vocabulary that teachers use in each language could be an indicator of the science information that children are learning. Although the impact of academic language has been investigated in other learning domains, there is limited research in science and across various languages (including Spanish) [37,47-50]. Previous research demonstrates that providing children with high-quality language improves their vocabulary and language outcomes $[37,49]$. Science is a learning domain that provides many opportunities to enrich children's vocabulary [51]. For this study, the term "academic science language" is used to describe high-quality vocabulary used by teachers within the classroom that relates to science.

Prior research investigating teacher use of academic science language in preschool has focused on creating science interventions to enrich children's vocabulary [26,47,51-55]. One study found that preschoolers and kindergarteners whose teachers participated in science interventions had higher vocabulary scores [51]. Additionally, research focused on teachers' use of academic language in the context of science has also demonstrated increases in children's use of academic vocabulary [47,54]. Nevertheless, to date, few studies have examined the academic language that teachers use naturally around science, without a fixed science intervention $[47,54]$. These studies also examined children's vocabulary and not children's science outcomes. Furthermore, academic science language and the impacts on Head Start Spanish-English DLL children in both English and Spanish have yet to be examined. The current study addresses this gap by capturing teachers' academic science language use in both English and Spanish in a structured science lesson and determining whether it relates to preschool DLL children's performance on science outcomes across languages.

\subsection{Current Study}

There is a gap in the literature regarding DLL children's performance in science across both of their languages. There is also a need to better understand factors that might contribute to their science scores. Most literature surrounding the importance of language of assessment and the role of children's dominant language focuses on the domain of language (e.g., vocabulary, syntax) and not on other critical learning areas such as science [24,31,32]. Furthermore, teacher-level impacts such as language use (i.e., English and/or Spanish) in the classroom could contribute to children's scores on language math, and social-emotional assessments $[34,36]$. However, to date, there are no studies that examine teachers' English and Spanish use specifically within the context of preschool science. Finally, prior studies indicate that the academic language that teachers use impacts children's outcomes [37,49]. Again, these findings typically examine children's language outcomes and not science performance. The current study aims to fill multiple gaps in the literature around science assessment for DLL children from under-resourced homes by answering the following research questions:

1. First, this study examines if, overall, DLL children performed significantly better on a science assessment in English or Spanish. Given the unique Spanish-dominant community of the study participants, this aim remains exploratory. DLL children in this sample may be enrolled in schools where teachers do not primarily speak English. Thus, children may hear more Spanish and perform better on Spanish science assessments if they enter preschool with more Spanish skills compared to English skills;

2. Second, this study examines whether dominant language impacts performance on a science assessment in English and Spanish. Based on previous literature, it is hypothesized that DLL children's dominant language will be associated with their scores on both English and Spanish science assessments [32]; 
3. Third, this study investigates the association between teachers' language of instruction (i.e., English and Spanish) during science lessons and DLL children's performance on an assessment of science learning in both English and Spanish. It is hypothesized that DLL children whose teachers use more English will perform better on the English science assessment. It is also hypothesized that DLL children whose teachers use more Spanish will have higher scores on science in Spanish $[34,56]$;

4. Fourth, this study examines the relation between the language of instruction when using academic science language on DLL children's performance on science assessments (i.e., English and Spanish). It is expected that DLL children whose teachers use more academic science language in English will have higher scores on the English science assessment [37]. Finally, it is hypothesized that DLL children whose teachers use a higher amount of academic science language in Spanish will have higher scores on the Spanish science assessment.

\section{Materials and Methods}

\subsection{Participants}

This cross-sectional study was conducted within the context of a larger study, Enfoque en Ciencia, with the participation of Head Start Centers across a large urban area in the Southeastern United States. Head Start is a federally funded preschool program in the United States. Head Start includes hundreds of early learning centers across the US that aim to ensure children from low-income homes have the academic and social-emotional skills to succeed in the K-12 education system. They mainly serve children between the ages of three and five who live in low-income households (i.e., below $130 \%$ of the federal poverty guidelines). Performance Standards issued by Head Start state that the program supports language development in both English and children's home language. However, no specific guidelines define the amount of English and Spanish that should be used [41]. The actual language used in Head Start classrooms depends on local programs and individual teachers (e.g., it could range from 5\% English to 95\% English). The classrooms in this study were not involved in purposeful bilingual or dual immersion programs. However, the schools in this study were located in areas where Spanish was very prevalent. Spanish was spoken by $66 \%$ of the population in Miami-Dade County, and 25\% spoke only English [57]. Centers $(N=8)$ participating in the larger project were informed about and consented to the current project including directors, teachers, teaching assistants, and families. Centers involved in this study used HighScope, a research-grounded curriculum that promotes active learning, yet at the time of data collection did not have a science-focused component.

The current study was housed within a larger project validating an early science assessment measure for Spanish-English-speaking children from under-resourced homes. There was no intervention involved, and the study consisted of assessing children in the fall and spring of the 2017-2018 academic year. Center directors were approached, and if they were interested in their center participating, teachers and parents were approached. Participation in the study was voluntary, and teachers and parents were asked for consent and provided with a detailed description of what the study involved (e.g., classroom observations, child assessments, etc.). In addition, parents had to return their signed consent form for their child to participate in the observation portion of the study. To participate in this study, and as a part of the larger study, children had to score at least a 2 out of 20 on the English language screener and a 6 out of 20 on the Spanish language screener. These cutoff scores were set purposefully low to capture a realistic representation of the DLL population. Additionally, these cutoffs were used to ensure that children had some level of English and Spanish, thus making them Spanish-English DLLs. The less stringent cutoff score for English follows the assumption that children who speak Spanish at home and are newly developing their English skills in school would be acquiring English skills during the study. A total of 255 Spanish-English DLL children participated in the current study in the 2017-2018 school year. Children ranged in age from 3 to 5 years old $(M=48.66, S D=6.60) ; 46 \%$ were girls, and $21 \%$ were English dominant. 
Lead and assistant teachers $(N=66)$ in this study were all female and had between 1 and 25 years of teaching experience $(M=12.52, S D=6.25)$. Eighty-two percent of teachers reported that Spanish was their primary language. Teachers in this study reported speaking varying levels of English and Spanish. Most teachers reported speaking Spanish "very well" $(\mathrm{n}=41)$ or "well" $(\mathrm{n}=10)$. Fewer teachers reported speaking Spanish "not well" $(\mathrm{n}=10)$ or "not at all" $(\mathrm{n}=5)$. Some teachers stated that they spoke English "very well" $(\mathrm{n}=14)$, while most reported speaking it "well" $(\mathrm{n}=22)$ or "not well" $(\mathrm{n}=22)$. Six teachers reported that they did not speak English at all. Teachers who agreed to take part in the study were given gift cards as compensation for their time spent participating in the study. Teachers were also asked if they had received any professional development around science. Overall, most teachers reported having a moderate $(n=35)$ or minimal $(n=15)$ amount of professional development around early science education. Some reported having a great deal $(n=12)$ of professional development around early science, and a few reported having no training in early science education $(n=4)$.

\subsection{Procedure}

Data collectors included undergraduate and graduate research assistants. All data collectors were rigorously trained on the administration of assessments. Most data collectors were Spanish-English bilinguals (88\%). The language screener was administered by bilingual research assistants as there were components that required administration (i.e., by the research assistants) and responses (i.e., from children) in English and Spanish. Because the science assessment was delivered on touchscreen laptops (i.e., all instructions and items were delivered by the program in English for the English version and in Spanish for the Spanish version), the research assistants only monitored administration (e.g., setting up the laptops, monitoring that children were staying on task).

Children were screened for language dominance in the fall of 2017 to determine their English and Spanish language abilities (see Measures Section below for more details). Dominant language results were used to counterbalance the order of administration for the science assessments. Thus, half of the English-dominant children received the Spanish science assessment first, while the other half received the English science assessment first. This counterbalancing procedure was also used for Spanish-dominant children. Administration of the science assessments in English and Spanish occurred in the spring of 2018.

Participating teachers reported their demographics and language proficiency in English and Spanish in the spring of 2018. Teachers also consented to be videorecorded while conducting a science lesson of their choosing. Videos were recorded in each classroom, one morning, for 15 to $20 \mathrm{~min}$. Teachers were asked to conduct a science lesson in whichever language(s) they typically used. They were allowed to choose whatever topic they wanted; most chose to perform a Physical Science lesson $(n=18)$. The next most frequent type of lesson chosen was Life Science $(n=8)$, followed by Earth and Space Science $(n=5)$ and Engineering and Technology $(\mathrm{n}=3)$.

Videos of science lessons were transcribed by research assistants using the Systematic Analysis of Language Transcripts (SALT) Software conventions [58]. Research assistants were trained using materials available on the SALT website (e.g., videos, practice audio files, and master transcripts). In line with SALT coding procedures, the resulting transcripts were segmented into C-Units, or "an independent clause with all of its modifiers" [58]. Transcripts were then coded for teachers' use of English and Spanish, use of academic words, and science language.

\subsection{Measures}

\subsubsection{Language Screener}

Children were assessed in the fall on the PreLAS2000 [59], a language screener for preschool children, available in English and Spanish. The PreLAS2000 was used to capture children's language abilities to determine language dominance and DLL eligibility to 
participate in the study. Two subtests were used for assessing English and Spanish, Simon Says and the Art Show. The Simon Says subtest contains ten items and measures children's receptive language ability, while the Art Show also contains ten items and captures children's expressive abilities. The use of these two subtests has been validated with ethnically diverse Head Start children [60]. Reliability for the "Simon Says" and "Art Show" subscales is high, with Cronbach's alphas of 0.88 and 0.90, respectively [59].

\subsubsection{Science Achievement}

Children were assessed in the spring using items from the Lens on Science [61] and Enfoque en Ciencia assessments to determine their knowledge of science concepts. Lens and Enfoque are the equated versions of the same science assessment; they only differ by the language of administration: English or Spanish. Lens and Enfoque items assess science knowledge as it relates to the Framework for K-12 Science Education [62] in the following areas: scientific and engineering practice skills, crosscutting concepts, and science content from "life science", "earth and space sciences", "technology and engineering", and "physical and energy sciences". Items cover a range of difficulty levels normed on a sample of 1750 English monolingual children and 1174 Spanish-English DLL preschoolaged children in Head Start. Children received equivalent forms of Lens and Enfoque, distributed evenly in both difficulty and in the content area, to ensure that the subsets of items chosen in English and Spanish were equivalent. Therefore, DLL children did not receive a more difficult form in either language. Items were calibrated using the dichotomous Rasch model scaled to have a mean item difficulty of zero and unit-logit metric. On this scale, 0 is the mean of the norming sample and 1 is the standard deviation. For example, if a child receives a score of 0 , it means they scored on average as well as children in the norming sample. If a child receives a 1, they scored a standard deviation above the mean, and if they receive a score of -1 , they would be one standard deviation below the mean. The average standard error of the Rasch ability estimate was 0.34 for both Lens and Enfoque, which is equivalent to a score reliability of 0.86 [61].

Lens and Enfoque are administered on the same touchscreen computer platform. Children are asked to sit in front of a touchscreen device, and items are presented visually to children one at a time. Children listen with headphones to prompts instructing them on how to respond. For example, an item measuring children's understanding of the concept of melting might show a picture of a strawberry inside an ice cube sitting in the sun. With the initial picture still visible, three choice pictures then appear below it, and children are instructed to "touch the picture that shows what the strawberry looks like after having sat in the sun". A trained research assistant supervises the test administration process. Prior to administration of the assessment, children must pass a screener, also administered on the touchscreen device. This screener demonstrates a child's ability to follow the instructions and correctly respond to each of the three item formats. The administration took approximately 20 minutes for each form.

\subsubsection{Quantity of Teacher English and Spanish}

Transcripts of teacher talk during the science lesson were coded using Atlas.ti software by research assistants. Each word spoken by a teacher was coded as "English" or "Spanish". All words were counted as "tokens", meaning that each time a word is used, it counted toward the total count of English or Spanish. For example, the word "animal" could be used once in English and twice in Spanish. "Animal" would then be coded as "English" once and "Spanish" twice. Words were not coded as English or Spanish if they were names, proper nouns, filled pause words (e.g., um, ah, ok, eh), or singing. These words were not coded because it was often difficult to determine what language the speaker intended to use. For example, a child's name could be "Daniela" and pronounced in English or Spanish. If the coder was not sure if a word was English or Spanish (e.g., metal, animal), they referred to the original video. 


\subsubsection{Teacher Academic Language}

To code teacher academic language, two lists of the words most commonly used and heard by DLL children were used to filter out "common" language [63]. If words were not included on this list, they were deemed "academic". The initial English list contained a total of 1109 word types (e.g., car). The Spanish list contained 949 word types. After filtering these words out, conjugations, verb tenses, plurals, and diminutives relating to the words on the lists were removed. According to the rules outlined by Schick et al. (2019), variations that changed words to adverbs were considered more sophisticated and left on the "academic" list. A total of 1360 English common words, including conjugations and plurals of words on the original lists (i.e., both car and cars), and 1714 Spanish common words were filtered out.

\subsubsection{Teacher Academic Science Language}

To determine how much academic science language teachers used, a codebook was created using the preschool version [64] of the K-12 Conceptual Science Framework [62]. A graduate student and undergraduate research assistants coded scientific and engineering practices and core ideas that teachers used in both English and Spanish. Science codes were coded at the C-Unit level. All research assistants were rigorously trained and passed reliability to code science language with a Krippendorf's alpha of 0.67 or higher [65]. For scientific and engineering practices, the average alpha was $a=0.82$, and for core ideas, $a=0.79$.

\section{Results}

\subsection{Descriptives}

All data were examined for outliers, skewness, kurtosis, and collinearity using SPSS version 26 [66]. All variables met the assumption of normality [67]. Before running analyses, continuous variables were centered. Descriptive statistics for children's Spanish and English science scores and teacher speech are displayed in Table 1. There were no differences between the average percentages of English $(M=47.97, S D=38.10)$ and Spanish $(M=52.03, S D=38.10)$ used by teachers, $t(33)=0.31, p=0.76$. In comparison to breakdowns of English and Spanish use in prior studies (see [36]), teachers used a good deal of Spanish overall. In $2.9 \%$ of science lessons, teachers used no Spanish. In $14.71 \%$ of science lessons, teachers used Spanish $<5 \%$ of the time. In $14.71 \%$ of classrooms, it was used between $5 \%$ and $25 \%$ of the time. In $14.71 \%$ of classrooms, teachers used Spanish between $25 \%$ and $50 \%$ of the time. Finally, in $52.94 \%$ of science lessons, teachers used Spanish more than $50 \%$ of the time during the lesson. On average, teachers used more Spanish academic science words $(M=74.74, S D=73.90)$ than English science academic words $(M=31.24, S D=35.91)$, $t(33)=2.80, p<0.01$.

Bivariate correlations for all variables including control variables were examined and are presented in Table 2. Children's English and Spanish science scores were moderately positively correlated $(r=0.52)$. Age was also moderately positively associated with children's English $(r=0.40)$ and Spanish $(r=0.45)$ science assessments. The overall percentage of teachers' English use was positively correlated with children's English science outcomes $(r=0.15)$, while the overall percentage of Spanish used was negatively related to children's English science outcomes $(r=-0.15)$. Teachers' use of Spanish academic science words was negatively associated with children's performance on the English science assessment $(r=-0.17)$.

Independent $t$ tests were conducted to determine whether there were significant differences between children's performance on English and Spanish equivalent forms. There were no significant differences between boys' $(M=-0.01, S D=0.85)$ and girls' $(M=-0.01, S D=0.85)$ English science assessments, $t(249)=1.40, p=0.16$. There were also no significant differences between boys' $(M=0.16, S D=0.97)$ and girls' $(M=0.32$, $S D=0.82)$ Spanish science assessments, $t(249)=0.03, p=0.98$. 
Table 1. Descriptive statistics for child and teacher level variable.

\begin{tabular}{|c|c|c|c|c|c|c|}
\hline & & $\mathbf{n}$ & $M$ & $S D$ & Min & Max \\
\hline \multirow{3}{*}{$\begin{array}{c}\text { Children's } \\
\text { English Science Assessment }\end{array}$} & Spanish Dominant & 197 & -0.12 & 0.81 & -2.11 & 2.69 \\
\hline & English Dominant & 54 & 0.39 & 0.90 & -1.31 & 2.34 \\
\hline & Overall & 251 & -0.01 & 0.85 & -2.11 & 2.69 \\
\hline \multirow{3}{*}{$\begin{array}{c}\text { Children's } \\
\text { Spanish Science Assessment }\end{array}$} & Spanish Dominant & 198 & 0.22 & 0.94 & -2.11 & 3.92 \\
\hline & English Dominant & 53 & 0.28 & 0.75 & -0.97 & 2.35 \\
\hline & Overall & 251 & 0.23 & 0.90 & -2.11 & 3.92 \\
\hline $\begin{array}{c}\text { Teachers' Percentage } \\
\text { of English }\end{array}$ & & 34 & $47.97 \%$ & 38.10 & 0.37 & 100.00 \\
\hline $\begin{array}{c}\text { Teachers' Percentage } \\
\text { of Spanish }\end{array}$ & & 34 & $52.03 \%$ & 38.10 & 0 & 99.63 \\
\hline $\begin{array}{l}\text { Teachers' Number of } \\
\text { English Words }\end{array}$ & & 34 & 651.91 & 626.46 & 5 & 2522 \\
\hline $\begin{array}{l}\text { Teachers' Number of } \\
\text { Spanish Words }\end{array}$ & & 34 & 784.15 & 677.36 & 0 & 2184 \\
\hline $\begin{array}{l}\text { Teachers' Number of English } \\
\text { Academic Science Words }\end{array}$ & & 34 & 31.24 & 35.91 & 0 & 143 \\
\hline $\begin{array}{l}\text { Teachers' Number of } \\
\text { Teachers' Spanish Academic } \\
\text { Science Words }\end{array}$ & & 34 & 74.74 & 73.90 & 0 & 230 \\
\hline
\end{tabular}

Note: Science scores are measured using the dichotomous Rasch model scaled to have a mean item difficulty of zero and a standard deviation of 1 .

Table 2. Bivariate correlations.

\begin{tabular}{|c|c|c|c|c|c|c|c|c|}
\hline & 1 & 2 & 3 & 4 & 5 & 6 & 7 & 8 \\
\hline \multicolumn{9}{|l|}{ 1. English Science Assessment } \\
\hline 2. Spanish Science Assessment & $0.52 * * *$ & & & & & & & \\
\hline 3. Age & $0.40^{* * *}$ & $0.45^{* * *}$ & & & & & & \\
\hline 4. Sex & -0.01 & -0.09 & 0.02 & & & & & \\
\hline 5. Dominant Language & $0.24^{* * *}$ & 0.02 & $0.13^{*}$ & $0.13 *$ & & & & \\
\hline 6. Percentage of English & $0.15^{*}$ & 0.05 & 0.12 & -0.03 & -0.01 & & & \\
\hline 7. Percentage of Spanish & $-0.15 *$ & -0.05 & -0.12 & 0.03 & 0.01 & $-1.00^{* * *}$ & & \\
\hline 8. Number of English Academic Science Words & 0.03 & 0.05 & 0.07 & 0.06 & 0.09 & $0.47^{* *}$ & $-0.34 *$ & \\
\hline 9. Number of English Academic Science Words & $-0.17 * *$ & -0.11 & -0.14 & 0.07 & -0.20 & $-0.87^{* * *}$ & $0.94 * * *$ & -0.27 \\
\hline
\end{tabular}

Note: ${ }^{*} p<0.05,{ }^{* *} p<0.01,{ }^{* * *} p<0.001$. Numbers $1-5$ are child level variables. Rows $6-9$ are teacher level variables.

\subsection{DLL Children's Science Outcomes in English and Spanish}

A repeated-measures ANCOVA was conducted using SPSS to examine potential differences in DLL children's performance on their English and Spanish science assessment. Results indicated that there was no difference between children's scores on English $(M=-0.01, S D=0.85)$ and Spanish $(M=0.23, S D=0.90)$ science assessments controlling for age and sex, $F(1,243)=0.17, p=0.68$.

Mplus version 8.3 [68] was used to examine aims 2 through 4 (i.e., 2. dominant language associated with children's science outcomes in English and Spanish, 3. the language of instruction associated with children's science outcomes in English and Spanish, and 4. teacher's academic science language related to DLL children's performance on science assessments in English and Spanish). Intraclass correlation coefficients (ICCs) were calculated to determine the amount of variance in children's science scores that is attributable to the classroom level. ICCs indicated that classroom-level factors comprised $0 \%$ of the variance in children's Spanish science assessment and $0.76 \%$ of the variance in children's English science assessment. As there was some variance at the classroom level in children's science outcomes, children were nested within classrooms (i.e., type = two-level).

\subsection{Dominant Language and Science Scores}

Hierarchical linear modeling was conducted for aim 2, to determine if dominant language was associated with children's science outcomes in English and Spanish. Model 
fit was good across multiple fit indices, including $X^{2}(3, N=255)=7.65, p>0.05$, RMSEA (0.08), CFI (0.96), and SRMR (0.05). When controlling for children's age and sex, dominant language was associated with children's English science scores, $b=0.20, p<0.01$; however, it did not relate to children's Spanish science scores, $b=-0.02, p=0.64$.

A follow-up repeated-measures ANCOVA was conducted for aim 2, to determine the nature of the relation between dominant language and language of assessment. There was no main effect for dominant language, $F(1,242)=2.99, p=0.09$. There were no significant differences between English-dominant and Spanish-dominant children's Spanish science scores. There was, however, an interaction between dominant language and performance on science assessments, $F(1,243)=11.20, p<0.001$, such that English-dominant children $(M=0.39, S D=0.90)$ performed significantly higher on English science assessments than Spanish-dominant children $(M=-0.12, S D=0.81)$. See Figure 1 for follow-up results examining differences between science scores based on dominant language.

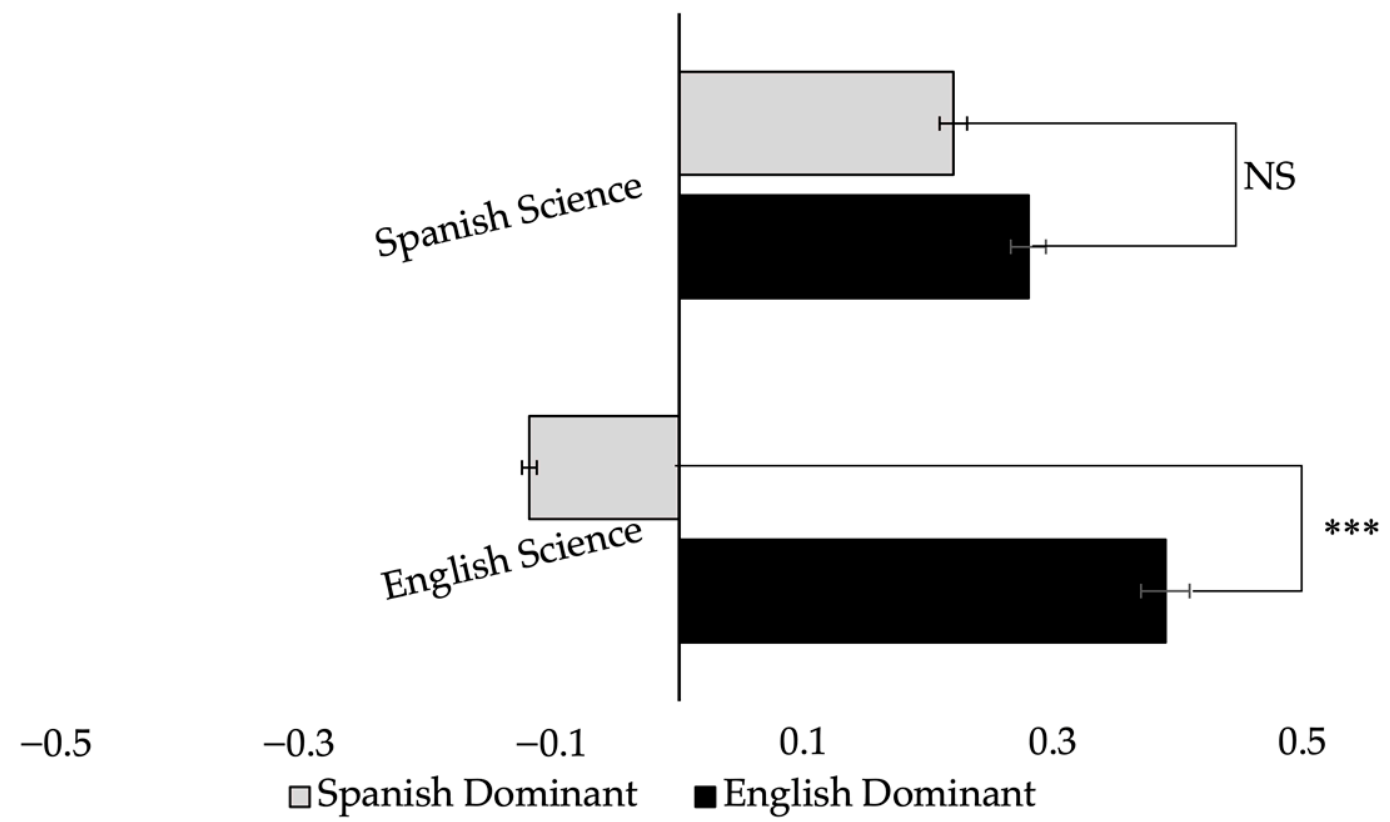

Figure 1. Note: ${ }^{* * *} p<0.001$. English and Spanish science scores by dominant language.

\subsection{Teachers' Use of English and Spanish in Structured Science Lessons}

To determine if the percentage of teachers' English and Spanish was associated with children's English and Spanish science scores, models were also run in Mplus, nesting children within classrooms. See Figure 2 for the conceptual model. When examining the relation between the percentage of English that teachers used during a science lesson and children's science outcomes, model fit was good, $X^{2}(3, N=255)=4.88, p>0.05$, RMSEA $=0.05$, CFI $=0.99$, and SRMR within $=0.03$, controlling for children's age, sex, and dominant language, and teachers' primary language. SRMR between (0.13) was decent. Teachers' English use did not predict children's English science scores $(b=0.90, p=0.06)$ or children's Spanish science scores, $b=-0.06, p=0.92$.

As the percentage of Spanish language used by teachers was linearly dependent upon their English percentage, model fit was also excellent for the model containing teachers percentage of Spanish, $X^{2}(3, N=255)=4.88, p>0.05$, RMSEA $=0.05, \mathrm{CFI}=0.99$, and SRMR within $=0.03$. SRMR between $(0.13)$ was decent. The percentage of Spanish used by teachers was not associated with children's English science assessments $(b=-0.90$, $p=0.06$ ) or children's Spanish science scores, $b=0.06, p=0.92$. 


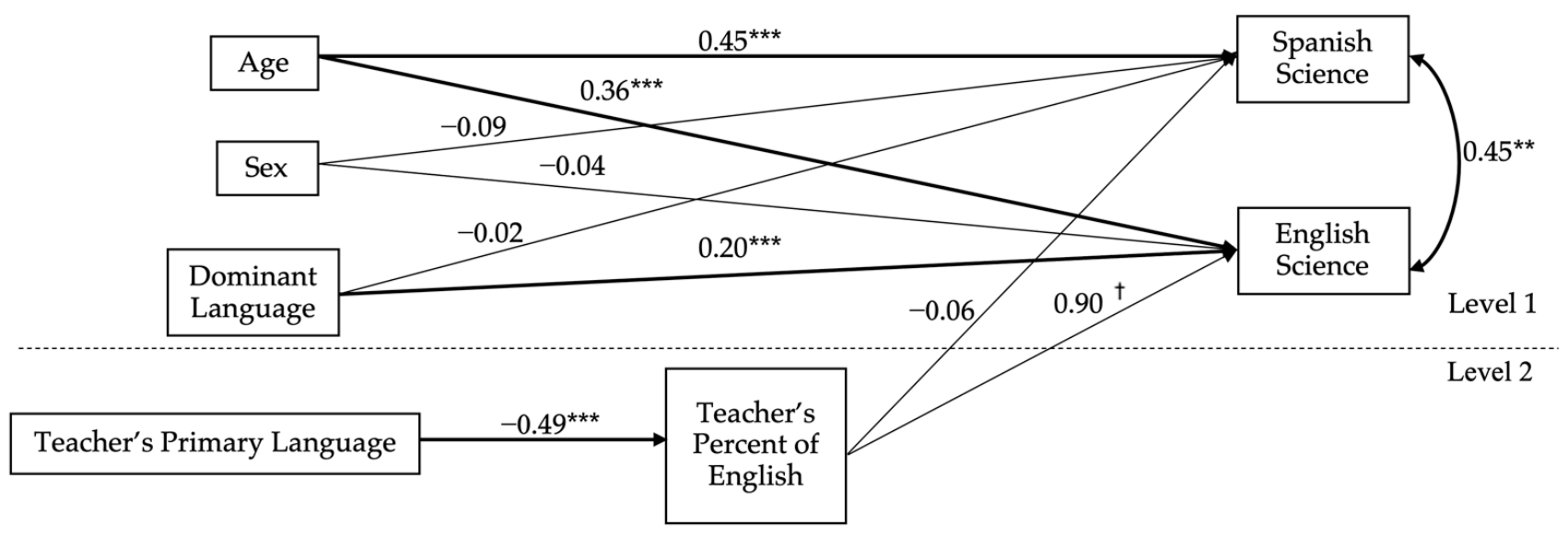

(a)

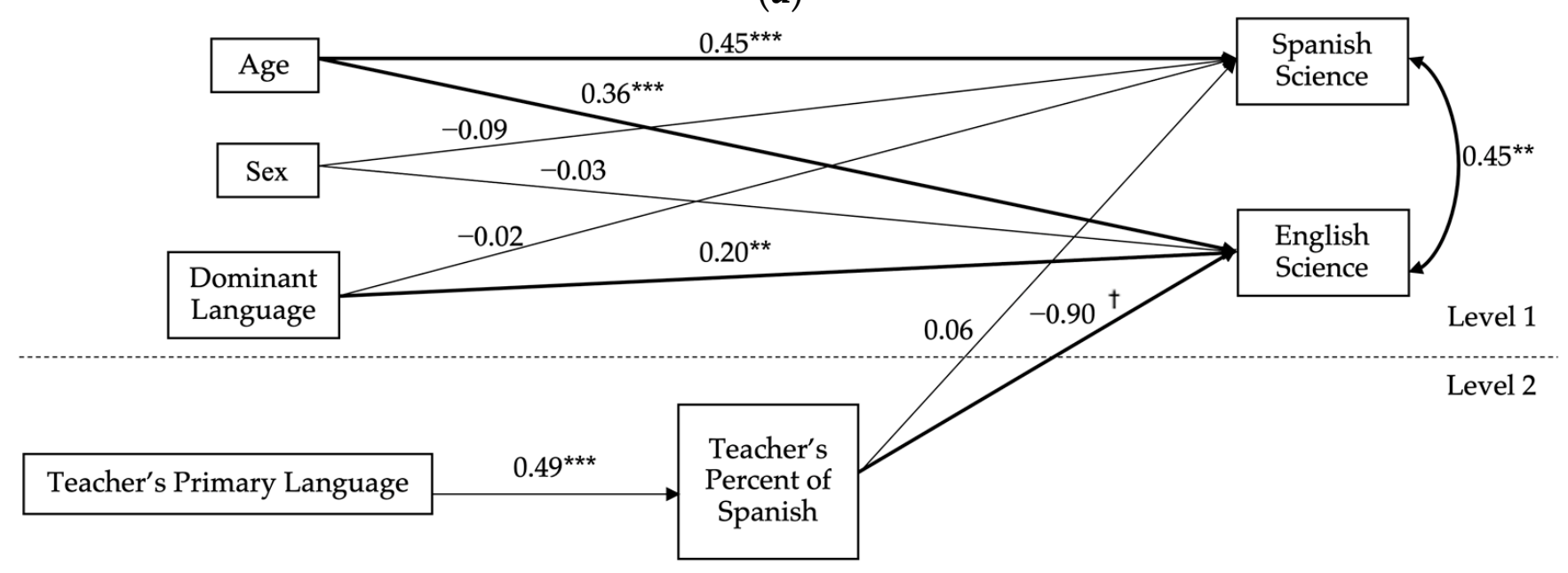

(b)

Figure 2. Note: ${ }^{\dagger} p<0.10,{ }^{* *} p<0.01,{ }^{* * *} p<0.001$. (a) Percentage of teachers' English associated with children's science outcomes; (b) percentage of teachers' Spanish associated with children's science outcomes.

\subsection{Teachers' Use of Academic Science Language English and Spanish in Structured Science Lessons}

Models were also run in Mplus to determine the relation between teachers' academic science language and children's science outcomes, nesting children within classrooms. For the model containing Teachers' use of academic science English, model fit was excellent according to the chi-square test of model fit $\left(X^{2}(8, N=255)=13.10, p=0.11\right)$, RMSEA $(0.05)$, CFI (0.97), and SRMR within (0.04). It was poor for SRMR between (0.27). Controlling for children's sex, age, and dominant language, teacher's primary language, teacher's highest education, and overall percentage of English used, teachers' academic science English was not associated with children's English $(b=-0.13, p=0.85)$ or Spanish science scores $(b=0.24, p=0.66)$. See Figure 3 for models.

When examining the relation between teachers' academic science language in Spanish and children's science scores, model fit was also excellent for the chi-square test of model fit $\left(X^{2}(8, N=255)=8.12, p>0.05\right)$, RMSEA (0.01), CFI (0.99), and SRMR within (0.03). It was poor for SRMR between (0.18). Teachers' academic science Spanish language was not related to children's Spanish science scores, $b=-0.29, p=0.59$. Academic science Spanish was negatively associated with children's English science scores, $b=-0.89, p=0.049$. The more academic science language that was used by teachers, the lower children's English science assessment scores were. 


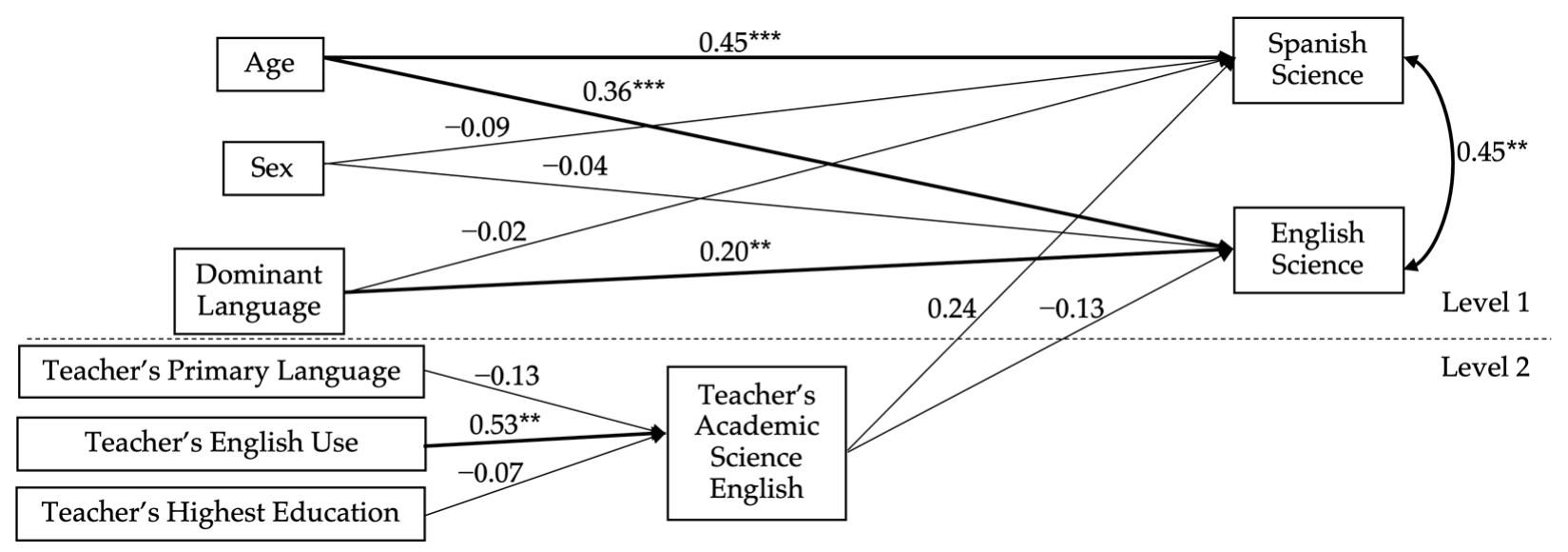

(a)

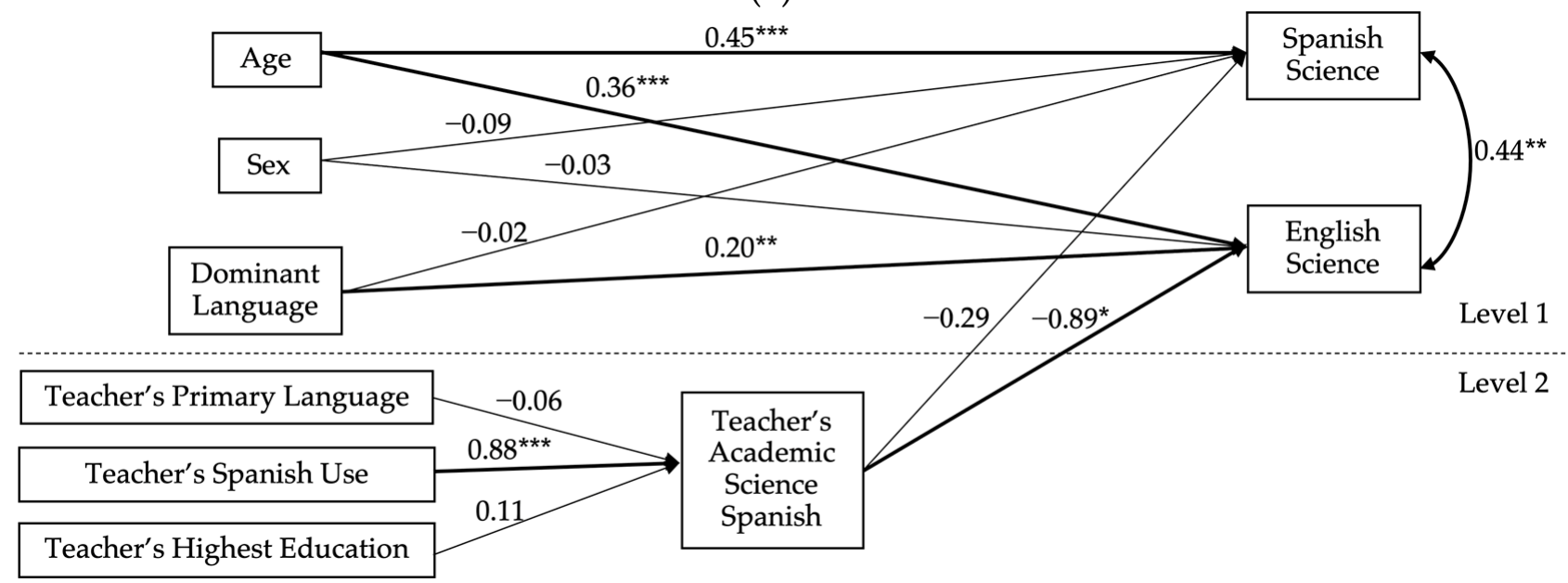

(b)

Figure 3. Note: ${ }^{*} p<0.05,{ }^{* *} p<0.01,{ }^{* * *} p<0.001$. (a) Teachers' academic science English associated with children's science outcomes; (b) teachers' academic science Spanish associated with children's science outcomes.

\section{Discussion}

The purpose of this study was to examine factors that might influence Spanish-English DLL children's performance on a science assessment in both of their languages. DLL children, when treated as a homogeneous group (i.e., when no distinctions between Englishand Spanish-dominant children were made), did not perform differently on English and Spanish science assessments. However, when examined as heterogeneous groups (i.e., English dominant versus Spanish dominant), Spanish-dominant children performed higher on their Spanish science assessment than their English science assessment. Teachers' use of academic science Spanish use was negatively related to DLL children's performance on the English science assessment. No other teacher language use affected children's performance on English or Spanish science assessments.

\subsection{Role of Language of Assessment in Performance}

\subsubsection{Assessment of DLL Children as a Homogeneous Versus a Heterogeneous Group}

DLL children are not a monolith. Thus, it is important to investigate how language differences within group [30,69], such as dominant language, affect assessment. When DLL children were assessed as a single homogeneous group, there were no differences in science scores between languages. This aim was exploratory; however, it was an important step in the analyses because it demonstrates the potential for an erroneous conclusion (i.e., that language of assessment does not matter). However, when dominant language was accounted for, children did perform differently on English and Spanish science assessments. 
It was hypothesized that dominant language would be associated with children's scores on both English and Spanish science assessments. However, this hypothesis was only partially supported, as dominant language only predicted performance on English assessments. English-dominant children performed higher on English science assessments than Spanishdominant children performed on English science assessments. There were no differences between Spanish- and English-dominant children's Spanish science scores.

This differential effect of language dominance suggests that it is especially important to consider the role of dominant language when assessing Spanish-dominant children. The results of this study align with previous research that suggests that Spanish-dominant DLL children tend to perform higher on measures assessed in their dominant language [20,32]. This study extends research examining DLL children's performance on language assessments, to early science, a domain that not only requires language skills but critical-thinking and problem-solving skills, as well [70,71]. Because Spanish-dominant children performed higher on Spanish science assessments, future studies and school programs should consider assessing DLL children in their dominant language (if not both languages) on measures of language and in other learning domains such as science.

\subsubsection{English-Dominant Children's Science Scores}

In contrast to prior studies which found that English-dominant children did not score as well on Spanish assessments [32], the current study found that English-dominant children were performing on par with their Spanish-dominant peers. This pattern may have emerged in the current sample for several key reasons. First, English-dominant children may have had high to moderately high language skills in both languages. Second, most of the children in the sample were Spanish dominant. Third, the majority of teachers in this study were proficient in Spanish and used it within the classroom. Finally, the community in which this study occurred was a Spanish-language dense area.

At the beginning of the school year, English-dominant children had an average English language score of 14.13 and an average Spanish score of 8.52 (both out of 20). On average, Spanish-dominant children began the school year with an English score of 5.71 and a Spanish score of 15.72. English-dominant children may be entering the preschool program with higher levels of Spanish than Spanish-dominant children have in English, as demonstrated by their Spanish language screener scores. However, this study did not measure children's language ability at the time of the science assessment in the spring, and thus, future studies should examine growth in Spanish skills over time.

Furthermore, on average, teachers reported having about $95.4 \%$ of their classroom comprising DLL children. The majority of DLL children sampled from the classrooms were Spanish dominant (i.e., $80 \%$ ). DLL children in this study were also still very young and may have only recently started school. Given the large proportion of Spanish-dominant peers, children may have had more opportunities to continue using Spanish within their classroom (as opposed to English). Given opportunities to interact with predominantly Spanish-dominant peers, it may be that English-dominant children had more occasions to use and improve their Spanish skills during the year.

Children in the current sample were enrolled in preschools where English and Spanish were both used frequently. When assessed as a single group, English-dominant DLL children may have performed equally well on English and Spanish science assessments because on average, they heard more Spanish during instruction (i.e., use of $47.97 \%$ English and $52.03 \%$ Spanish) than in previous studies, thus allowing them to continue developing their home language $[34,36,37,45]$. Teachers used Spanish, on average, over half of the time, whereas teachers in other studies typically spoke Spanish much less, if it was used at all $[34,36,37,45,46]$.

Additionally, the metropolitan area in which this study took place has the highest population of Hispanics in the US [72]. Over 66\% [22] of the people in this area report speaking Spanish, while nationally, only $12.85 \%$ [73] of the population reports speaking Spanish. Within this area of the country, the maintenance of Spanish may be more desirable 
due to cultural norms [57]. Reports of language use in this metropolitan area demonstrate that Spanish is used by people of all socioeconomic statuses (SES), including people of higher income. Researchers indicate that the continued use of Spanish by people of all SES levels may lead to Spanish being highly valued and perpetuate the use of the language within the region [57]. Prevalence of Spanish within the community may promote teachers' and children's use of Spanish in the classroom, which may be another reason why Englishdominant children in this sample performed equally on science assessments.

\subsection{Percentage of Teacher English and Spanish Use}

The percentage of English and Spanish that teachers used in the classroom was not significantly associated with children's science scores. These findings did not align with prior studies which demonstrated that when teachers used more Spanish, children performed higher on measures of academic achievement $[34,36,38]$. Previous literature found that in classrooms where teachers used "some Spanish" (observer report of $49 \%$ on average), children had higher Spanish abilities [38]. In the current study, teachers used about as much Spanish as in the previous literature. However, Spanish language use did not affect children's Spanish science scores. One factor that could impact how teacher language affects children's assessment performance is classroom quality [34,36,38]. Classrooms where teachers used some Spanish had higher ratings of quality than classrooms where teachers did not [38]. It was in these high-quality, "some Spanish" classrooms where children exhibited higher gains in Spanish language. Additionally, in classrooms with more Spanish used by the teacher and higher quality teacher emotional support, children had higher reading and math scores [34]. The current study did not control for classroom quality in its analysis of teacher Spanish and English use, which may account for the null findings. Despite the null findings, this study contributes to the literature on teacher language use with DLL children by providing a detailed examination of the quantity of English and Spanish (i.e., word-by-word analysis instead of self-report, observer report, or time sampling) in the context of a science lesson.

\subsection{Academic Science Language in Preschool Classrooms}

The amount of academic science language teachers used in Spanish was inversely associated with children's science scores in English. Academic science language in English did not predict children's outcomes in science as hypothesized. An overwhelming number of studies have demonstrated that academic language positively relates to children's vocabulary outcomes $[37,48-50]$. However, these studies did not investigate the impacts of teachers' academic language use on DLL children or science assessments.

Academic science Spanish may have been inversely related to children's English scores because it was highly correlated with the amount of English and Spanish that teachers were using. That is, teachers who used more academic science Spanish tended to use more Spanish overall, and less English overall. It may be that the children in this sample were exposed to more Spanish overall, including within science settings. Children's primary exposure to English is likely through their teachers, so when teachers use less English, children do not perform as well on their English science assessments. Although teachers used more academic science Spanish, this should not be considered detrimental to children's science scores, as previous studies have demonstrated the importance of Spanish in DLL preschool classrooms [34,36,38]. Alternatively, this finding suggests a need to also consider the language use of teachers when deciding what language(s) to use when assessing Spanish-English DLL children's science.

Additionally, English and Spanish academic science language was dispersed between two languages for teachers and children. This study took a unique perspective in examining both English and Spanish children's science scores; however, it may be important to take a more holistic approach when examining the impacts of academic language on children's science outcomes. Most prior studies examining the impact of academic language on children's outcomes were conducted with teachers who only used English and only 
investigated children's English scores [49,50]. One study did find that when teachers used more complex language in English, it was positively associated with children's bilingual outcomes [37]. It is possible that the effects of a combination of teachers' academic science language in English and Spanish may predict a combination of DLL children's English and Spanish science scores (i.e., a conceptual score). Studies examining the efficacy of conceptual scoring have found that it improved DLL children's performance on language assessments above their scores when tested in only one language [74,75]. Despite the importance of conceptual scoring, past studies have predominantly examined its effects in the context of language abilities and do not extend it to other domains, such as science.

Furthermore, it is possible that teacher academic science language alone, without good pedagogy, does not positively relate to children's science outcomes. Science is a relatively new area of focus in early childhood education, and most preschool classrooms do not include it as part of their curriculum [76,77]. Thus, it may have been rare for a teacher to intentionally incorporate science into their lesson plans. This study attempted to circumvent the lack of intentional science present in early childhood education by examining academic language as it related to the Early Science Framework (e.g., coding for Scientific and Engineering Practices and Core Ideas) in context. Similar studies examined teachers' use of math language and found that when high-quality math pedagogy was paired with a strong understanding of the content, teacher language was associated with children's outcomes in math [78]. The present study may not have found similar results because it only captured the content of the lesson and not pedagogy or the teacher's understanding of science content. For the teacher's academic science language to have a positive effect on children's science scores, it may be necessary to ensure that teachers have a good pedagogy to enact an effective science lesson. Teachers may also need to have a strong understanding of children's developmental level and be able to balance this with both science content and good pedagogy. Thus, it may be important to pair academic language with a measure of science lesson quality. Measures that assess the quality of preschool science lessons are becoming more readily available $[79,80]$. Future studies should consider controlling for the quality of the science lesson when examining teachers' academic science language.

\subsection{Implications for Practice}

The present study has implications for researchers, practitioners, and policymakers. First, this work brings attention to an understudied learning domain, i.e., early science. Children are naturally curious about the world around them and express great motivation for learning science during the preschool years [81]. Young children ask questions about why things happen (e.g., “Why don't my shoes fit anymore?"), constantly carry out experiments (e.g., dropping a sippy cup off of a highchair to see if a caregiver will pick it up each time), and make observations (e.g., "It's too cold!") [82]. Despite this early motivation to engage in scientific inquiry, by high school, students' motivation around scientific inquiry declines [83]. This demonstrates a need to begin supporting children's scientific curiosity early and to continue fostering it as they develop. However, to date, many studies focus on language, math, and social-emotional skills. This study sought to highlight the importance of support in this early learning domain by examining factors that related to DLL children's science outcomes.

Results from this study indicate that it is important for teachers working with DLL children to be cognizant of the language in which they administer assessments. This is especially true for DLL children who are Spanish dominant. When Spanish-dominant children were assessed in English, they performed worse on English science assessments, illustrating a need for researchers and practitioners to screen DLL children for their dominant language before administering assessments or to administer them in both languages. It is also important for researchers, practitioners, and policymakers to be critical when interpreting scores from DLL children. For example, if an English science assessment is 
given to a Spanish-dominant child, educators and stakeholders should recognize that their score may not accurately represent their science abilities.

Although the language of instruction did not always impact children's outcomes, this study provides insight into the language that early childhood teachers use with DLL children in the context of science. Teachers' use of academic science Spanish did impact children's English science outcomes, indicating that teacher language use is an important factor to consider when assessing DLL children. This study can be particularly useful for metropolitan areas where Spanish is more prevalent in the community and may be affecting patterns of loss or maintenance.

Findings from this study can also inform practice in early childhood at a national level by providing information about how the home language and English are being supported within classrooms, specifically within the context of science instruction. Within the context of this study, teachers on average demonstrated that they used both English and Spanish equally, showing that these sites are implementing early education best practices (i.e., Head Start Performance Standards) around support for DLL development [41].

\subsection{Limitations and Future Directions}

The important implications for researchers, practitioners, and policymakers from this study suggest a number of future research directions. To better understand the nature of the difference between DLL children's English and Spanish science scores, future studies may want to include a larger sample of children. Although not statistically significant, there was a trend level finding, where the percentage of English that teachers used positively predicted children's English science scores. Given a larger sample, this may have been statistically significant and might indicate that Spanish-English DLL children's English science assessments are influenced by teachers. However, further studies are needed to determine if that is the case.

A larger sample should also include more English-dominant children or potentially delve deeper into the heterogeneity amongst DLLs. English-dominant children only comprised $20 \%$ of the sample in this study. Future studies may also take a more nuanced perspective of DLLs and examine not only the role of language dominance but that of balance, as prior studies have implicated it as a key factor in DLL children's cognitive development $[17,18]$.

Future studies should also examine how these results might extend to other groups of DLL or multilingual learning children. While in the US, Spanish-English DLLs are the most populous group of DLLs, there are many other DLL children nationally and globally. The findings of this study could extend to other DLL children who are exposed to a mainstream language and a home language, where it may be important to screen DLL children for their stronger language prior to administering a science assessment. Results from this study could also extend to DLLs who are learning two languages that are similar (e.g., English and French). However, future research is needed to determine if findings apply in other contexts.

Additionally, it may be important to incorporate classrooms that speak primarily Spanish or English to better understand how teacher talk influences children's learning and performance on assessments. While teachers in this sample reported speaking a mix of English and Spanish, 82\% reported that Spanish was their primary language. These results may therefore generalize to Head Start sites that employ teachers who have strong Spanish skills. However, one limitation is that they may not generalize to classrooms where teachers are less proficient in Spanish.

In addition, some teachers may more regularly engage in early science experiences with children in their classrooms. This may have led to differences in levels of teachers' comfort in carrying out science lessons or differences in knowledge about early science. Moving forward, it is critical that studies collect more information about teachers' own comfort with early science and the frequency in which they teach it. 
Furthermore, there is a need for a longitudinal study to investigate children's science scores in English and Spanish over time, to understand how their language grows and develops. This includes examining multiple timepoints for language and science measures, to better understand DLL children's abilities at the beginning and end of the school year as well as across years. Lastly, there is a need to examine other factors that may influence DLL language development, such as children's home language environment and exposure to science at home.

\section{Conclusions}

Engaging young children in scientific inquiry early on provides them with the opportunity to build critical thinking skills necessary to secure one of the growing numbers of science careers in the future [2]. Recently, there has been a national focus on the importance of promoting science in early childhood education. Although science has recently been brought to the forefront in early education, there are science achievement gaps that begin early and persist over time for Hispanic DLL children and children from under-resourced homes [15]. Research with children from under-resourced homes in other school readiness domains highlights the importance of investigating and intervening at an early age [84-86]. The current study contributes to the literature by implicating dominant language as an important factor when assessing Spanish-English DLL Head Start children in classrooms where a mix of Spanish and English occurs. This study also found associations between teachers' use of academic science Spanish and children's English science outcomes, findings which indicate that children's English science scores may be impacted more by teacher language than DLL children's Spanish science scores. This demonstrates a need to account for classroom language use when assessing DLLs. Finally, this study did not find positive associations between academic science language and children's science scores, indicating that classroom quality or quality of a science lesson may be necessary to detect these effects in the future.

Author Contributions: Conceptualization, B.R., D.B.G. and E.F.; methodology, B.R. and D.B.G.; formal analysis, B.R. and E.F; investigation, B.R., E.F. and D.B.G.; resources, D.B.G. and K.H.-P.; data curation, B.R.; writing—original draft preparation, B.R. and D.B.G.; writing-review and editing, B.R., E.F., K.H.-P. and D.B.G.; visualization, B.R. and E.F.; supervision, B.R., E.F., and D.B.G.; project administration, B.R., E.F. and D.B.G.; funding acquisition, B.R. and D.B.G.; All authors have read and agreed to the published version of the manuscript.

Funding: This research was funded by the Office of Planning Research and Evaluation, grant number GR011545, and Institute of Education Sciences grant number R305A130612.

Institutional Review Board Statement: The study was conducted according to the guidelines of the Declaration of Helsinki, and approved by the Institutional Review Board of the University of Miami (Protocol\# 20171061, 18 January 2018).

Informed Consent Statement: Informed consent was obtained from all subjects involved in the study.

Data Availability Statement: The data presented in this study are available on request from the corresponding author.

Acknowledgments: We truly appreciate the openness and willingness of the centers involved in the study. We would like to acknowledge and thank the University of Miami School Readiness Lab for working tirelessly to help to collect and code the data.

Conflicts of Interest: The authors declare no conflict of interest. The funders had no role in the design of the study; in the collection, analyses, or interpretation of data; in the writing of the manuscript, or in the decision to publish the results.

\section{References}

1. Noonan, R. STEM Jobs: 2017 Update; Brief \#02-17; Department of Commerce: Washington, DC, USA, 2017.

2. Employment in STEM Occupations. Available online: https://www.bls.gov/emp/tables/stem-employment.htm (accessed on 4 June 2021). 
3. 6 Facts about the STEM Workforce. Available online: http:/ / pewrsr.ch/2EpARr1 (accessed on 4 June 2021).

4. Key Facts about, U.S. Latinos for National Hispanic Heritage Month. Available online: https:/ / pewrsr.ch/2oH4TEC (accessed on 4 June 2021).

5. Committee on Supporting English Learners in STEM Subjects; Board on Science Education; Board on Children, Youth, and Families; Division of Behavioral and Social Sciences and Education; National Academies of Sciences, Engineering, and Medicine. English Learners in STEM Subjects: Transforming Classrooms, Schools, and Lives; Francis, D., Stephens, A., Eds.; National Academies Press: Washington, DC, USA, 2018; p. 25182. [CrossRef]

6. Bandel, E.; Atkins-Burnett, S.; Castro, D.C.; Smither Wulsin, C.; Putnam, M. Examining the Use of Language and Literacy Assessments with Young Dual Language Learners; FPG Child Development Institute, Center for Early Care and Education: Chapel Hill, NC, USA, 2012.

7. Gutiérrez, K.D.; Zepeda, M.; Castro, D.C. Advancing Early Literacy Learning for All Children. Educ. Res. 2010, 39, 334-339. [CrossRef]

8. Dual Language Learning: What Does It Take? Head Start Dual Language Report. Available online: https:/ / www.buildinitiative. org/Portals / / Uploads / Documents / Dual\%20Language\%20Learning\%20-\%20What\%20Does\%20It\%20Take.pdf (accessed on 4 June 2021).

9. Baker, C.; Wright, W.E. Foundations of Bilingual Education and Bilingualism, 6th ed.; McNaughton \& Gunn Ltd.: Blue Ridge Summit, PA, USA, 2017.

10. Dual Language Learners. Available online: http://www.childtrends.org/indicators/dual-language-learners (accessed on 1 January 2021).

11. Childhood Poverty Among Hispanics Sets Record, Leads Nation. Available online: https://www.pewresearch.org/hispanic/2011/09/ 28/childhood-poverty-among-hispanics-sets-record-leads-nation/ (accessed on 4 June 2021).

12. Statistical Portrait of Hispanics in the United States. 2015. Available online: https://www.pewresearch.org/hispanic/2017/09/ 18/2015-statistical-information-on-hispanics-in-united-states / (accessed on 4 June 2021).

13. Duncan, G.J.; Dowsett, C.J.; Claessens, A.; Magnuson, K.; Huston, A.C.; Klebanov, P.; Pagani, L.S.; Feinstein, L.; Engel, M.; Brooks-Gunn, J.; et al. School readiness and later achievement. Dev. Psychol. 2007, 43, 1428-1446. [CrossRef]

14. Golinkoff, R.M.; Hoff, E.; Rowe, M.L.; Tamis-LeMonda, C.; Hirsh-Pasek, K. Language Matters: Denying the Existence of the 30-Million-Word Gap Has Serious Consequences. Child Dev. 2019, 90, 985-992. [CrossRef] [PubMed]

15. Morgan, P.L.; Farkas, G.; Hillemeier, M.M.; Maczuga, S. Science Achievement Gaps Begin Very Early, Persist, and Are Largely Explained by Modifiable Factors. Educ. Res. 2016, 45, 18-35. [CrossRef]

16. Barac, R.; Bialystok, E. Bilingual Effects on Cognitive and Linguistic Development: Role of Language, Cultural Background, and Education. Child Dev. 2012, 83, 413-422. [CrossRef]

17. Thomas-Sunesson, D.; Hakuta, K.; Bialystok, E. Degree of bilingualism modifies executive control in Hispanic children in the USA. Int. J. Biling. Educ. Biling. 2016, 21, 197-206. [CrossRef] [PubMed]

18. White, L.J.; Greenfield, D.B. Executive functioning in Spanish- and English-speaking Head Start preschoolers. Dev. Sci. 2016, 20 , e12502. [CrossRef]

19. Barrueco, S.; López, M.; Ong, C.; Lorzano, P. Assessing Spanish-English Bilingual Preschoolers: A Guide to Best Approaches and Measures; Paul H Brookes Publishing: Baltimore, MD, USA, 2012.

20. Guzman-Orth, D.; Lopez, A.A.; Tolentino, F. A Framework for the Dual Language Assessment of Young Dual Language Learners in the United States. ETS Res. Rep. Ser. 2017, 2017, 1-19. [CrossRef]

21. Bronfenbrenner, U.; Morris, P.A. The Bioecological Model of Human Development. In Handbook of Child Psychology; John Wiley and Sons: Hoboken, NJ, USA, 2007.

22. Carter, P.M.; Lynch, A. Multilingual Miami: Current Trends in Sociolinguistic Research. Lang. Linguist. Compass 2015, 9, 369-385. [CrossRef]

23. Aikens, N.; West, J.; McKee, K.; Moiduddin, E.; Atkins-Burnett, S.; Xue, Y. Screening approaches for determining the language of assessment for dual language learners: Evidence from Head Start and a universal preschool initiative. Early Child. Res. Q. 2020, 51, 39-54. [CrossRef]

24. Peña, E.D.; Halle, T.G. Assessing Preschool Dual Language Learners: Traveling a Multiforked Road. Child Dev. Perspect. 2011, 5, 28-32. [CrossRef]

25. Lee, O.; Buxton, C.; Lewis, S.; Leroy, K. Science inquiry and student diversity: Enhanced abilities and continuing difficulties after an instructional intervention. J. Res. Sci. Teach. 2006, 43, 607-636. [CrossRef]

26. Spycher, P. Learning Academic Language through Science in Two Linguistically Diverse Kindergarten Classes. Elem. Sch. J. 2009, 109, 359-379. [CrossRef]

27. Cummins, J. Bilingualism and Special Education: Program and Pedagogical Issues. Learn. Disabil. Q. 1983, 6, 373-386. [CrossRef]

28. Moll, L.C.; Amanti, C.; Neff, D.; Gonzalez, N. Funds of knowledge for teaching: Using a qualitative approach to connect homes and classrooms. Theory Pr. 1992, 31, 132-141. [CrossRef]

29. McWayne, C.; Greenfield, D.B.; Zan, B.; Mistry, J.; Ochoa, W. A Comprehensive Professional Development Approach for Supporting Science, Technology, and Engineering Curriculum in Preschool: Connecting Contexts for Dual Language Learners. In Supporting Children's Well-Being During Early Childhood Transition to School; IGI Global: Hershey, PA, USA, 2021 ; pp. $222-253$.

30. Lambert, R.G.; Kim, D.-H.; Durham, S.; Burts, D.C. Differentiated rates of growth across preschool dual language learners. Biling. Res. J. 2017, 40, 81-101. [CrossRef] 
31. Goodrich, J.M.; Lonigan, C.J.; Kleuver, C.G.; Farver, J.M. Development and transfer of vocabulary knowledge in Spanish-speaking language minority preschool children. J. Child Lang. 2015, 43, 969-992. [CrossRef] [PubMed]

32. Hammer, C.S.; Lawrence, F.R.; Miccio, A.W. Exposure to English Before and After Entry into Head Start1: Bilingual Children's Receptive Language Growth in Spanish and English. Int. J. Biling. Educ. Biling. 2008, 11, 30-56. [CrossRef]

33. Montanari, S.; Ochoa, W.; Subrahmanyam, K. A longitudinal investigation of language mixing in Spanish-English dual language learners: The role of language proficiency, variability, and sociolinguistic factors. J. Child Lang. 2019, 46, 1-25. [CrossRef]

34. Burchinal, M.; Field, S.; Lopez, M.L.; Howes, C.; Pianta, R. Instruction in Spanish in pre-kindergarten classrooms and child outcomes for English language learners. Early Child. Res. Q. 2012, 27, 188-197. [CrossRef]

35. Jia, G.; Kohnert, K.; Collado, J.; Aquino-Garcia, F. Action Naming in Spanish and English by Sequential Bilingual Children and Adolescents. J. Speech Lang. Hear. Res. 2006, 49, 588-602. [CrossRef]

36. Chang, F.; Crawford, G.; Early, D.; Bryant, D.; Howes, C.; Burchinal, M.; Barbarin, O.; Clifford, R.; Pianta, R. Spanish-Speaking Children's Social and Language Development in Pre-Kindergarten Classrooms. Early Educ. Dev. 2007, 18, 243-269. [CrossRef]

37. Franco, X.; Bryant, D.M.; Gillanders, C.; Castro, D.C.; Zepeda, M.; Willoughby, M.T. Examining linguistic interactions of dual language learners using the Language Interaction Snapshot (LISn). Early Child. Res. Q. 2019, 48, 50-61. [CrossRef]

38. Raikes, H.H.; White, L.; Green, S.; Burchinal, M.; Kainz, K.; Horm, D.; Bingham, G.; Cobo-Lewis, A.; St. Clair, L.; Greenfield, D.; et al. Use of the Home Language in Preschool Classrooms and First- and Second-Language Development among Dual-Language Learners. Early Child. Res. Q. 2019, 47, 145-158. [CrossRef]

39. De Abreu, P.M.J.E.; Cruz-Santos, A.; Tourinho, C.J.; Martin, R.; Bialystok, E. Bilingualism Enriches the Poor. Psychol. Sci. 2012, 23, 1364-1371. [CrossRef]

40. Limlingan, M.C.; McWayne, C.M.; Sanders, E.A.; López, M.L. Classroom Language Contexts as Predictors of Latinx Preschool Dual Language Learners' School Readiness. Am. Educ. Res. J. 2019, 57, 339-370. [CrossRef]

41. Head Start Program Performance Standards. Available online: https:/ / eclkc.ohs.acf.hhs.gov/policy/45-cfr-chap-xiii (accessed on 6 February 2021).

42. Durgunoğlu, A.Y.; Segers, E.; Broek, P.V.D. An updated review of cross-language transfer and its educational implications. In Developmental Perspectives in Written Language and Literacy; John Benjamins Publishing Company: Amsterdam, The Netherlands, 2017; pp. 167-182.

43. Goodrich, J.M.; Namkung, J.M. Correlates of reading comprehension and word-problem solving skills of Spanish-speaking dual language learners. Early Child. Res. Q. 2019, 48, 256-266. [CrossRef]

44. Melby-Lervåg, M.; Lervåg, A. Cross-linguistic transfer of oral language, decoding, phonological awareness and reading comprehension: A meta-analysis of the correlational evidence. J. Res. Read. 2011, 34, 114-135. [CrossRef]

45. Sawyer, B.; Atkins-Burnett, S.; Sandilos, L.; Hammer, C.S.; Lopez, L.; Blair, C. Variations in Classroom Language Environments of Preschool Children Who Are Low Income and Linguistically Diverse. Early Educ. Dev. 2018, 29, 398-416. [CrossRef] [PubMed]

46. Jacoby, J.W.; Lesaux, N.K. Support for Extended Discourse in Teacher Talk with Linguistically Diverse Preschoolers. Early Educ. Dev. 2014, 25, 1162-1179. [CrossRef]

47. Menninga, A.; Van Dijk, M.; Wetzels, A.; Steenbeek, H.; Van Geert, P. Language use in kindergarten science lessons: Language production and academic language during a video feedback coaching intervention in kindergarten science lessons. Educ. Res. Eval. 2017, 23, 26-51. [CrossRef]

48. Aarts, R.; Demir-Vegter, S.; Kurvers, J.; Henrichs, L.F. Academic Language in Shared Book Reading: Parent and Teacher Input to Mono- and Bilingual Preschoolers. Lang. Learn. 2016, 66, 263-295. [CrossRef]

49. Barnes, E.M.; Dickinson, D.K. The Relationship of Head Start Teachers' Academic Language Use and Children's Receptive Vocabulary. Early Educ. Dev. 2017, 28, 794-809. [CrossRef]

50. Dickinson, D.K.; Porche, M.V. Relation Between Language Experiences in Preschool Classrooms and Children's Kindergarten and Fourth-Grade Language and Reading Abilities. Child Dev. 2011, 82, 870-886. [CrossRef] [PubMed]

51. Guo, Y.; Wang, S.; Hall, A.H.; Breit-Smith, A.; Busch, J. The Effects of Science Instruction on Young Children's Vocabulary Learning: A Research Synthesis. J. Fam. Econ. Issues 2015, 44, 359-367. [CrossRef]

52. Llosa, L.; Lee, O.; Jiang, F.; Haas, A.; O'Connor, C.; Van Booven, C.D.; Kieffer, M.J. Impact of a Large-Scale Science Intervention Focused on English Language Learners. Am. Educ. Res. J. 2016, 53, 395-424. [CrossRef]

53. Taboada, A.; Rutherford, V. Developing Reading Comprehension and Academic Vocabulary for English Language Learners Through Science Content: A Formative Experiment. Read. Psychol. 2011, 32, 113-157. [CrossRef]

54. Henrichs, L.F.; Leseman, P.P. Early Science Instruction and Academic Language Development Can Go Hand in Hand. The Promising Effects of a Low-Intensity Teacher-Focused Intervention. Int. J. Sci. Educ. 2014, 36, 2978-2995. [CrossRef]

55. Hong, S.-Y.; Diamond, K.E. Two approaches to teaching young children science concepts, vocabulary, and scientific problemsolving skills. Early Child. Res. Q. 2012, 27, 295-305. [CrossRef]

56. Collins, B.A. Dual language development of Latino children: Effect of instructional program type and the home and school language environment. Early Child. Res. Q. 2014, 29, 389-397. [CrossRef] [PubMed]

57. Population Data for County: Miami-Dade. Available online: http://www.miamidadematters.org/demographicdata?id=414\& sectionId=935\#sectionPiece_97 (accessed on 4 June 2021).

58. Miller, J.F.; Andriacchi, K.; Nockerts, A. Assessing Language Production Using SALT Software: A Clincian's Guide to Language Sample Analysis; SALT Software LLC: Middleton, WI, USA, 2011. 
59. Duncan, S.E.; De Avila, E.A. PreLAS 2000; CTB/McGraw-Hill: Monterey, CA, USA, 1998.

60. Rainelli, S.; Bulotsky-Shearer, R.J.; Fernandez, V.A.; Greenfield, D.B.; López, M. Validity of the first two subtests of the preschool language assessment scale as a language screener for Spanish-speaking preschool children. Early Child. Res. Q. 2017, 38, 10-22. [CrossRef]

61. Greenfield, D.B. Assessment in Early Childhood Science Education. In Research in Early Childhood Science Education; Metzler, J.B., Ed.; Springer Netherlands: Dordrecht, The Netherlands, 2015; pp. 353-380.

62. National Research Council. A Framework for K-12 Science Education: Practices, Crosscutting Concepts, and Core Ideas; National Academies Press: Washington, DC, USA, 2012.

63. Schick, A.; Melzi, G.; Wuest, C.; Scarola, L. The Gap in the Word Gap: The Use of Sophisticated Words by and with Preschoolers. 2021; Unpublished manuscript.

64. Greenfield, D.B.; Alexander, A.; Frechette, E. Unleashing the Power of Science in Early Childhood: A Foundation for High-Quality Interactions and Learning. Zero Three 2017, 37, 13-21.

65. Hayes, A.F.; Krippendorff, K. Answering the Call for a Standard Reliability Measure for Coding Data. Commun. Methods Meas. 2007, 1, 77-89. [CrossRef]

66. George, D.; Mallery, P. SPSS for Windows Step by Step: A Simple Guide and Reference 120 Update, 5th ed.; Pearson Education: Auckland, New Zealand, 2005.

67. Curran, P.J.; West, S.G.; Finch, J.F. The robustness of test statistics to nonnormality and specification error in confirmatory factor analysis. Psychol. Methods 1996, 1, 16-29. [CrossRef]

68. Muthén, L.K.; Muthén, B. Mplus User's Guide, 8th ed.; CRC: Los Angeles, CA, USA, 2017.

69. Winsler, A.; Burchinal, M.R.; Tien, H.-C.; Peisner-Feinberg, E.; Espinosa, L.; Castro, D.C.; LaForett, D.R.; Kim, Y.K.; De Feyter, J. Early development among dual language learners: The roles of language use at home, maternal immigration, country of origin, and socio-demographic variables. Early Child. Res. Q. 2014, 29, 750-764. [CrossRef]

70. Nayfeld, I.; Fuccillo, J.; Greenfield, D.B. Executive functions in early learning: Extending the relationship between executive functions and school readiness to science. Learn. Individ. Differ. 2013, 26, 81-88. [CrossRef]

71. Bustamante, A.; White, L.J.; Greenfield, D.B. Approaches to learning and school readiness in Head Start: Applications to preschool science. Learn. Individ. Differ. 2017, 56, 112-118. [CrossRef]

72. Mapping the Latino Population by State, County, and City. Available online: https://www.pewresearch.org/hispanic/2013/08/ 29/mapping-the-latino-population-by-state-county-and-city/ (accessed on 4 June 2021).

73. Detailed Languages Spoken at Home and Ability to Speak English for the Population 5 Years and over: 2009-2013. Available online: https:/ / www.census.gov / data/tables/2013/demo/2009-2013-lang-tables.html (accessed on 4 June 2021).

74. Core, C.; Hoff, E.; Rumiche, R.; Señor, M. Total and Conceptual Vocabulary in Spanish-English Bilinguals From 22 to 30 Months: Implications for Assessment. J. Speech Lang. Hear. Res. 2013, 56, 1637-1649. [CrossRef]

75. Gross, M.; Buac, M.; Kaushanskaya, M. Conceptual Scoring of Receptive and Expressive Vocabulary Measures in Simultaneous and Sequential Bilingual Children. Am. J. Speech Lang. Pathol. 2014, 23, 574-586. [CrossRef]

76. Brenneman, K. Assessment for Preschool Science Learning and Learning Environments. Early Child. Res. Pract. ECRP 2011, 13, n1.

77. Greenfield, D.B.; Jirout, J.; Dominguez, X.; Greenberg, A.; Maier, M.; Fuccillo, J. Science in the Preschool Classroom: A Programmatic Research Agenda to Improve Science Readiness. Early Educ. Dev. 2009, 20, 238-264. [CrossRef]

78. McCray, J.S.; Chen, J.-Q. Pedagogical Content Knowledge for Preschool Mathematics: Construct Validity of a New Teacher Interview. J. Res. Child. Educ. 2012, 26, 291-307. [CrossRef]

79. Kaderavek, J.N.; North, T.; Rotshtein, R.; Dao, H.; Liber, N.; Milewski, G.; Molitor, S.C.; Czerniak, C.M. SCIIENCE: The creation and pilot implementation of an NGSS-based instrument to evaluate early childhood science teaching. Stud. Educ. Eval. 2015, 45, 27-36. [CrossRef]

80. Vitiello, V.E.; Whittaker, J.V.; Mulcahy, C.; Kinzie, M.B.; Helferstay, L. Reliability and Validity of the Preschool Science Observation Measure. Early Educ. Dev. 2018, 30, 196-215. [CrossRef]

81. Patrick, H.; Mantzicopoulos, P. Young Children's Motivation for Learning Science. In Research in Early Childhood Science Education; Cabe Trundle, K., Saçkes, M., Eds.; Springer: Dordrecht, The Netherlands, 2015; pp. 7-34. [CrossRef]

82. Klahr, D.; Matlen, B.; Jirout, J. Children as Scientific Thinkers. In Handbook of the Psychology of Science; Feist, G.J., Gorman, M.E., Eds.; Springer: New York, NY, USA, 2013; pp. 223-247.

83. Gottfried, A.E.; Fleming, J.S.; Gottfried, A.W. Continuity of academic intrinsic motivation from childhood through late adolescence: A longitudinal study. J. Educ. Psychol. 2001, 93, 3-13. [CrossRef]

84. Buysse, V.; Peisner-Feinberg, E.; Páez, M.; Hammer, C.S.; Knowles, M. Effects of Early Education Programs and Practices on the Development and Learning of Dual Language Learners: A Review of the Literature. Early Child. Res. Q. 2014, 29, 765-785. [CrossRef]

85. Castro, D.C.; Gillanders, C.; Franco, X.; Bryant, D.M.; Zepeda, M.; Willoughby, M.T.; Méndez, L.I. Early Education of Dual Language Learners: An Efficacy Study of the Nuestros Niños School Readiness Professional Development Program. Early Child. Res. Q. 2017, 40, 188-203. [CrossRef]

86. Yazejian, N.; Bryant, D.; Freel, K.; Burchinal, M. High-Quality Early Education: Age of Entry and Time in Care Differences in Student Outcomes for English-Only and Dual Language Learners. Early Child. Res. Q. 2015, 32, 23-39. [CrossRef] 